\title{
Estudo fitoquímico e análise mutagênica das folhas e inflorescências de Erythrina mulungu (Mart. ex Benth.) através do Teste de Micronúcleo em roedores
}

\author{
DE BONA, A.P. ${ }^{1}$; BATITUCCI, M.C.P. ${ }^{1 *}$; ANDRADE, M.A. ${ }^{2}$; RIVA, J.A.R. ${ }^{1}$; PERDIGÃO, T.L'. \\ ${ }^{1}$ Laboratório de Citogenética Vegetal, Departamento de Ciências Biológicas, Centro de Ciências Humanas e \\ Naturais, Universidade Federal do Espírito Santo, Avenida Marechal Campos, 1468, Campus de Maruípe, CEP: \\ 29040-090, Vitória-Brasil ²Curso de Farmácia da Universidade Federal do Pará, Brasil "docarmo_batitucci@ \\ yahoo.com.br
}

\begin{abstract}
RESUMO: Este trabalho teve como objetivo investigar a composição química, estabelecer a dose letal média $\left(D_{50}\right)$ e avaliar os potenciais efeitos mutagênicos do extrato hidroalcoólico de folhas e inflorescências de Erythrina mulungu Mart. ex Benth por meio do teste de micronúcleo em medula óssea de camundongos. Os ensaios fitoquímicos foram realizados através de reações preliminares com mudança de coloração e/ou formação de precipitado; $a \mathrm{DL}_{50}$, por meio da administração intraperitoneal de três concentrações dos extratos, avaliando-se o número de óbitos após 48 horas e o teste de micronúcleo foi feito por meio do método do esfregaço, após exposição dos animais a cinco dias de tratamento. Os resultados fitoquímicos demonstraram presença de açúcares redutores, fenóis e taninos, proteínas e aminoácidos, flavonóides, alcalóides, depsídeos e depsidonas e derivados de cumarina em ambos os órgãos; saponinas espumídicas e esteróides e triterpenóides nas folhas e glicosídeos cardiotônicos e antraquinônicos e alcalóides nas inflorescências. Para $\mathrm{a} \mathrm{DL}_{50}$ a folha demonstrou-se atóxica e a inflorescência moderadamente tóxica. Para o teste de micronúcleo, os resultados indicaram ausência de citotoxicidade e genotoxicidade dosedependente para as folhas e independente da dose para as inflorescências. Assim, esses resultados sugerem que a planta, nas condições analisadas, possui potencial para induzir danos ao DNA.
\end{abstract}

Palavras-chave: Erythrina mulungu, composição química, DL50, micronúcleo

\begin{abstract}
Phytochemical and mutagenic analysis of leaves and inflorescences of Erythrina mulungu (Mart. Ex Benth) through micronucleus test in rodents. This study aimed to investigate the chemical composition, to establish the mean lethal dose $\left(\mathrm{LD}_{50}\right)$ and to assess the potential mutagenic effects of hydroalcoholic extract of leaves and inflorescences of Erythrina mulungu Mart. ex Benth by using micronucleus test in bone marrow of mice. Phytochemical assays were carried out through preliminary reactions with color change and/or precipitate formation; the $\mathrm{LD}_{50}$ was obtained by intraperitoneal administration of three concentrations of the extracts, assessing the number of deaths after 48 hours, and the micronucleus test was done by the smear method, after exposure of animals to five days of treatment. Phytochemical results showed the presence of reducing sugars, phenols and tannins, proteins and amino acids, flavonoids, alkaloids, depsides, depsidones and coumarin derivatives in both organs; foaming and steroidal saponins and triterpenes in the leaves and cardiotonic and anthraquinonic glycosides and alkaloids in the inflorescences. Considering the $\mathrm{LD}_{50}$, the leaf was atoxic and the inflorescence was moderately toxic. As regards the micronucleus test, results indicated absence of cytotoxicity while genotoxicity was dose-dependent for leaves and dose-independent for inflorescences. Thus, these results suggest that the plant, under the tested conditions, has the potential to induce damages to the DNA.
\end{abstract}

Key words: Erythrina mulungu, chemical composition, LD50, micronucleus

Recebido para publicação em 16/12/2010

Aceito para publicação em 29/12/2011

Rev. Bras. PI. Med., Botucatu, v.14, n.2, p.344-351, 2012. 


\section{INTRODUÇÃO}

A utilização de espécies vegetais para o tratamento, cura ou prevenção de doenças é uma prática terapêutica bastante antiga, que atualmente tem sido revalorizada (Carvalho, 2004; Bieski, 2005; Turolla \& Nascimento, 2006).

A E. mulungu, encontrada na parte central do Brasil e popularmente conhecida como mulungu, é uma espécie utilizada para diferentes ações farmacológicas, atuando principalmente, como sedativa e hipotensiva (Lorenzi \& Matos, 2002).

Estudos são extremamente importantes, pois ainda existe a crença de que as plantas medicinais, por serem utilizadas a milhares de anos, apresentam eficácia comprovada e ausência de efeitos colaterais e riscos à saúde. Contudo, o uso de produtos derivados de plantas, pode levar a diversos agravos à saúde, como reações alérgicas, reações tóxicas, efeitos adversos e efeitos mutagênicos (Alves, 2004), já que muitas plantas que possuem poder curativo, podem apresentar substâncias tóxicas ou composição química variável (Capasso et al., 2000), que podem desencadear reações adversas devido aos próprios componentes ou pela presença de contaminantes ou adulterantes presentes nas preparações fitoterápicas (Silva et al., 2001).

Dessa forma, faz-se necessário que os produtos fitoterápicos sejam tratados como medicamentos, e sejam submetidos a estudos científicos para a avaliação da eficácia e segurança, a fim de legitimá-los como recurso terapêutico benéfico e eficaz para a humanidade e estabelecer padrões de identidade e qualidade para as diversas preparações utilizadas.

Dentre os testes utilizados para a avaliação da genotoxicidade e/ou mutagenicidade, o teste de micronúcleo em medula óssea de roedores in vivo é amplamente aceito e recomendado pelas agências internacionais e instituições governamentais, como parte de uma bateria de testes para avaliação e registro de novos produtos químicos e farmacêuticos, visando detectar e quantificar a ação mutagênica e/ou antimutagênica de agentes indutores (Fagundes et al., 2005; Leite et al., 2006).

Assim, o presente trabalho teve como objetivo investigar a composição química, estabelecer a dose letal média $\left(D_{50}\right)$ e avaliar os potenciais efeitos mutagênicos do extrato hidroalcoólico de folhas e inflorescências de Erythrina mulungu Mart. ex Benth por meio do teste de micronúcleo em medula óssea de camundongos.

\section{MATERIAL E MÉTODO}

\section{Material botânico}

Os galhos da planta E. mulungu foram coletados no Horto Municipal de Vitória, localizado no município de Cariacica-ES (Brasil) e parte do material foi utilizado para a produção de exsicatas depositadas no Herbário VIES/UFES sob o número de tombo VIES26312.

\section{Obtenção do extrato}

Para obtenção do extrato hidroalcóolico, as inflorescências e as folhas foram submetidas à secagem em estufa, com circulação de ar, à $40^{\circ} \mathrm{C}$, e após completamente secas, as mesmas foram pulverizadas, utilizando-se moedor elétrico.

Os extratos foram obtidos através da maceração do pó da folha ou da inflorescência em etanol $70 \%$, a temperatura ambiente ( 25 a $\left.30^{\circ} \mathrm{C}\right)$, e ao abrigo da luz, por 72 horas. Após esse período, foi realizada a filtração a vácuo dos extratos em rota-evaporador a pressão reduzida e temperatura de $60^{\circ} \mathrm{C}$, com a finalidade de remover o solvente, sem alteração dos componentes químicos dos extratos. Os extratos foram mantidos na geladeira até o momento da realização dos protocolos experimentais. As concentrações dos extratos utilizadas neste estudo foram baseadas na massa seca do extrato. Os extratos foram dissolvidos em água destilada para obtenção das frações aquosas.

\section{Prospecção fitoquímica}

A partir dos extratos hidroalcoólicos das folhas e inflorescências, utilizando-se a metodologia descrita por Barbosa (2004), foram realizadas reações para detecção preliminar de alguns grupos de constituintes dos metabólitos secundários dos vegetais, tais como saponina espumídica, açúcares redutores, polissacarídeos, fenóis e taninos, proteínas e aminoácidos, flavonóides e suas classes, alcalóides, depsídeos e depsidonas, derivado de cumarina, esteróides e triterpenóides, glicosídeos cardiotônicos e glicosídeos antraquinônicos.

Estabelecimento da dose letal média $\left(\mathrm{DL}_{50}\right)$ Para estabelecimento da dose letal média $\left(\mathrm{DL}_{50}\right)$ foram usados camundongos Swiss (30-50 g), obtidos no biotério da Universidade Federal do Espírito Santo (UFES) e realizada com base na metodologia de Litchfield e Wilcoxon (Garín-Aguilar et al., 2000). Os animais foram divididos em três grupos experimentais $(n=10)$, mantidos em gaiolas e, tratados com a o extrato hidroalcóolico de $E$. mulungu, em diferentes doses (250, 500 e 1000 $\mathrm{mg} \mathrm{kg}^{-1}$ ), por via intraperitoneal, em delineamento inteiramente casualizado. O volume administrado da dose foi proporcional à massa corpórea de cada animal. Os animais foram mantidos em local com temperatura e ciclo noite-dia controlado, e alimentação ad libitum. Após 48 horas foram observados e contados o número de óbitos. 


\section{Teste de micronúcleo}

Para a realização da análise de micronúcleos foram utilizados camundongos machos e fêmeas, adultos jovens com idade entre 7 a 12 semanas e saudáveis, obtidos no biotério da UFES. Os animais foram pesados, selecionados ao acaso e separados em diferentes grupos experimentais. Os animais foram mantidos com alimentação ad libitum em local com temperatura e ciclo noite-dia controlado.

A preparação do material para posterior análise foi realizada segundo metodologia descrita por Ribeiro (2003). O extrato vegetal foi administrado, em diferentes concentrações (200 e $400 \mathrm{mg} \mathrm{kg}^{-1}$ ), por gavage, de acordo com o grupo experimental. Foram estabelecidos o grupo controle negativo (CN), que recebeu o veículo (soro fisiológico 0,9\%) e o controle positivo (CP), que recebeu ciclofosfamida (50 $\left.\mathrm{mg} \mathrm{kg}^{-1}\right)$. Para a realização do teste de micronúcleo (MN) foram retiradas amostras de medula óssea dos fêmures coletados dos animais logo após esses serem eutanasiados pela técnica do deslocamento cervical.

Após a retirada da medula óssea dos fêmures dos camundongos, com auxílio de uma seringa, previamente preenchida com soro fetal bovino, 0 material foi ressuspendido no soro por várias vezes, com auxílio de pipeta Pasteur, até a obtenção de suspensão homogênea. A suspensão foi centrifugada, por 5 minutos, a $1000 \mathrm{rpm}$, o sobrenadante foi descartado e o sedimento ressuspendido em $0,5 \mathrm{~mL}$ de soro fetal bovino.

Pelo método de esfregaço, foram confeccionadas duas lâminas para cada animal, de cada um dos grupos experimentais. As lâminas foram secas ao ar, fixadas em metanol por 10 minutos e após 24 horas foram coradas, pelo método de Leishman, para diferenciar eritrócito policromático (EPC) do eritrócito normocromático (ENC).

O número de eritrócitos, com micronúcleos, foi determinado pela análise de um total de 2000 EPCs para cada animal, sendo 5 animais por tratamento, levando-se em consideração o número de EPCs micronucleados (EPCMN) e a razão EPC/EPC+ENC.

A análise estatística foi realizada através do método Qui-Quadrado $\left(\chi^{2}\right)$ (Beiguelman, 2006).

\section{RESULTADO E DISCUSSÃO}

Os resultados da prospecção fitoquímica preliminar em ambos os extratos hidroalcóolicos das folhas e inflorescências de E. mulungu (Tabela 1) indicaram a presença de açúcares redutores, fenóis

TABELA1. Ensaios fitoquímicos dos extratos hidroalcóolicos das folhas e das inflorescências de E. mulungu.

\begin{tabular}{|c|c|c|}
\hline Ensaios fitoquímicos & Folha & Inflorescência \\
\hline Saponina Espumídica & +++ & - \\
\hline Açúcares Redutores & +++ & +++ \\
\hline Polissacarídeos & - & - \\
\hline Fenóis e Taninos & +++ & +++ \\
\hline Proteínas e Aminoácidos & +++ & +++ \\
\hline Flavonóides ++ & +++ & \\
\hline \multicolumn{3}{|l|}{ Alcalóides } \\
\hline Drangendorff & + & + \\
\hline Bouchardat & + & $+/-$ \\
\hline Mayer & - & - \\
\hline Ácido Pícrico & - & + \\
\hline Depsídeos e Depsidonas & +++ & +++ \\
\hline Derivados de Cumarina & ++ & +++ \\
\hline Esteróides e Triterpenóides & +++ & - \\
\hline \multicolumn{3}{|l|}{ Glicosídeos Cardiotônicos } \\
\hline Anel Lactônico & - & +++ \\
\hline Desoxi-Açúcares & - & +++ \\
\hline Glicosídeos Antraquinônicos & - & + \\
\hline
\end{tabular}

Legenda: (-) negativo, (+/-) falso positivo, (+) fracamente positivo, $(++)$ positivo, (+++) fortemente positivo. 
e taninos, proteínas e aminoácidos, flavonóides, alcalóides, depsídeos e depsidonas, derivados de cumarina e esteróides e triterpenóides. A saponina espumídica e esteróides e triterpenóides são compostos presentes exclusivamente nos extratos das folhas de $E$. mulungu. Já os alcalóides (ácido pícrico), glicosídeos cardiotônicos e glicosídeos antraquinônicos somente foram detectados no extrato hidroalcóolico das inflorescências. Entretanto os polissacarídeos e alcalóides, de acordo com o método Mayer, não foram detectados em nenhum dos extratos.

Em estudos anteriores, Pino-Rodríguez et al. (2004) observaram que as folhas de E. fusca, assim como as folhas de E. mulungu, apresentam alcalóides, flavonóides, cumarinas, saponinas, açúcares redutores e triterpenos/esteróides. Contudo, detectaram em folhas de E. fusca, a presença de glicosídeos cardiotônicos, presentes apenas nas inflorescências de $E$. mulungu, e a ausência de fenóis e taninos, presentes tanto nas folhas quanto nas inflorescências de E. mulungu. Além disso, os autores observaram também em E. fusca, a presença de lactonas e carotenóides.

Almeida (2010) verificou a presença de alcalóides, taninos e glicosídeos antraquinônicos na casca de E. falcata. No extrato hidroalcóolico das inflorescências de E. mulungu analisadas neste trabalho estas substâncias foram detectadas. Tanto na casca como no extrato hidroalcóolico das inflorescências de E. mulungu não foram observadas saponinas. Na casca de E. falcata, não foi verificado glicosídeo cardiotônico, entretanto este componente foi identificado no extrato hidroalcóolico das inflorescências de E. mulungu.

Assim como nas folhas de E. mulungu, detectaram-se alcalóides, flavonóides, esteróides, triterpenóides, fenóis, taninos catéquicos e pirogáticos e saponinas, além da presença de heterosídeos cianogênicos nas folhas de E. velutina (Araujo Neto, 2008).

Com relação à classe dos flavonóides, observou-se que nas folhas estão presentes catequinas, flavonas, flavonóis e xantonas, enquanto que nas inflorescências detectou-se a presença de antocianinas e antocianidinas, chalconas e auronas, flavanonóis, leucoantocianidinas e flavanonas (Tabela 2).

$\mathrm{Na}$ casca do caule de E. mulungu foram detectadas flavanonas e leucoantocianidinas, assim como nas inflorescências, e a presença de xantonas, também encontrada nas folhas (Lima et al., 2006).

Nas folhas de E. velutina, assim como nas folhas de E. mulungu, foram detectados flavonas, flavonóis, xantonas e catequinas. Além disso, a prospecção fitoquímica de $E$. velutina indicou também a presença de auronas, chalconas, flavanonas, flavanonóis e leucoantocianidinas, encontrados nas inflorescências de E. mulungu (Araujo Neto, 2008).

No ensaio de toxicidade aguda em camundongos $\left(\mathrm{DL}_{50}\right)$, realizado com as folhas de $E$. mulungu, mesmo após 48 horas de exposição, não foi observado nenhum óbito, o que indica que esse extrato não apresenta toxicidade aguda.

Da mesma forma, estudo toxicológico para determinar a toxicidade aguda do extrato aquoso das folhas de E. velutina, indicou que a administração aguda é atóxica por via oral em ratos, uma vez que não foram observados mortalidade ou sintomas adversos após a administração da dose limite de $5 \mathrm{~g}$ $\mathrm{kg}^{-1}$ (Silva, 2008).

O ensaio utilizando o extrato hidroalcóolico da inflorescência, por sua vez, determinou uma $\mathrm{DL}_{50}$ igual a $1,37 \mathrm{~g} \mathrm{~kg}^{-1}$ (Figura 1), apresentando-se como um agente moderadamente tóxico, (Leite \& Amorim, 2006).

$A L_{50}$ da inflorescência de E. mulungu apresentou valores intermediários entre o encontrado

TABELA 2. Classe dos flavonóides presentes nos extratos hidroalcóolicos das folhas e das inflorescências de $E$. mulungu.

\begin{tabular}{lccc}
\hline Classe dos flavonóides & pH & Folha & Inflorescência \\
\hline Antocianinas/Antocianidinas & $\mathbf{3}$ & - & + \\
& $\mathbf{8 . 5}$ & - & - \\
Flavonas/Flavonóis/Xantonas & $\mathbf{1 1}$ & - & - \\
Chalconas/Auronas & $\mathbf{1 1}$ & + & - \\
& $\mathbf{3}$ & - & + \\
Flavanonóis & $\mathbf{1 1}$ & - & - \\
Leucoantocianidinas & $\mathbf{1 1}$ & - & + \\
Catequinas & $\mathbf{3}$ & - & + \\
Flavanonas & $\mathbf{3}$ & + & - \\
Legenda: (-) negativo, (+) fracamente positivo. & $\mathbf{1 1}$ & - & + \\
\hline
\end{tabular}

Rev. Bras. PI. Med., Botucatu, v.14, n.2, p.344-351, 2012. 


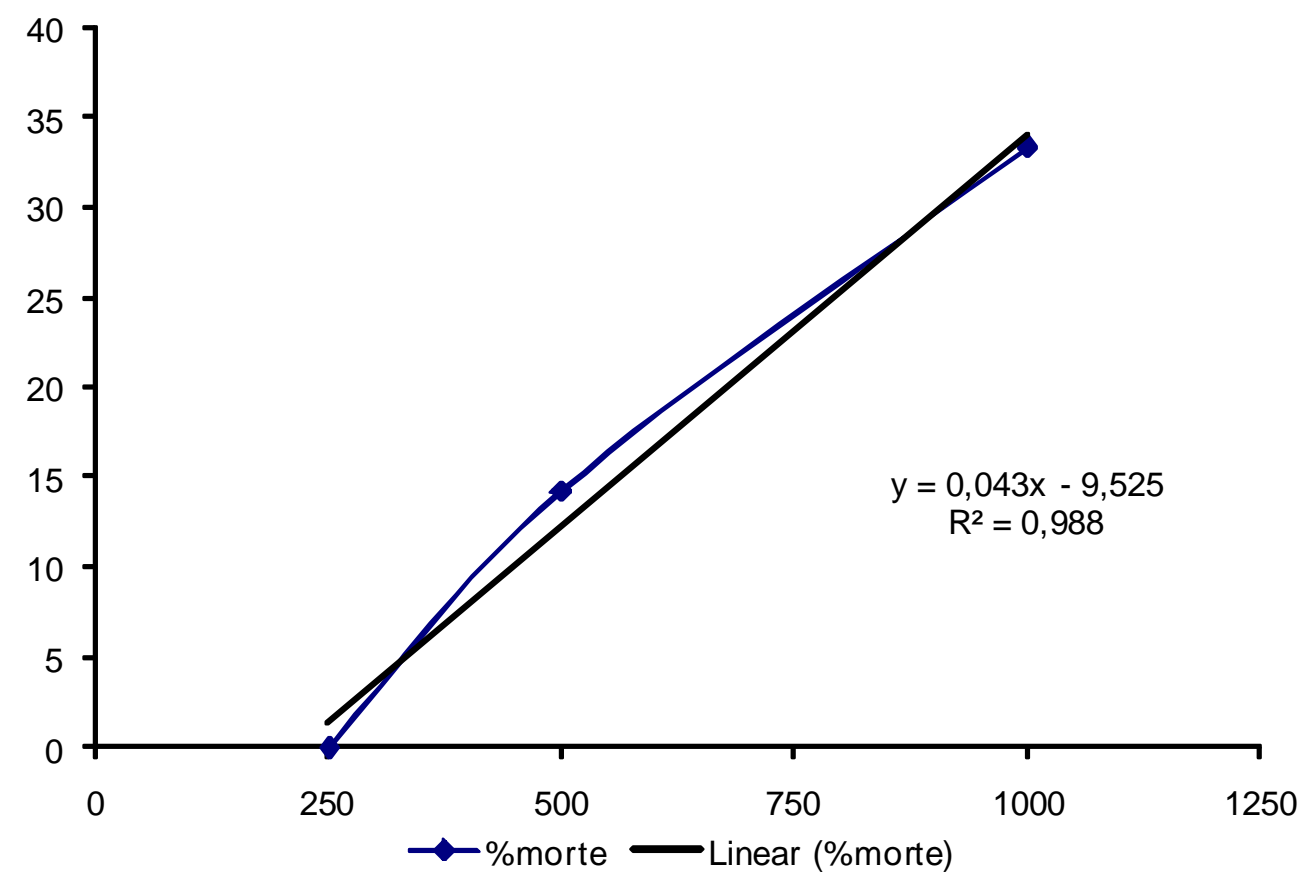

FIGURA 1. Toxicidade aguda em camundongos, frente ao extrato hidroalcoólico das inflorescências de Erythrina mulungu Mart ex. Benth, após 48 horas de exposição.

para a casca de E. senegalensis que foi aproximadamente $450 \mathrm{mg} \mathrm{kg}^{-1}$ (Saidu et al., 2000) e para E. falcata, que apresentou dose intermediária entre $3,75 \mathrm{~g} \mathrm{~kg}^{-1}$ e $5,0 \mathrm{~g} \mathrm{~kg}^{-1}$ (Cerutti et al., 2000).

Os resultados reforçam que metabólitos secundários apresentam-se de formas distintas nos diferentes órgãos vegetais, tanto em conteúdo como nas proporções disponíveis (Gobbo-Neto \& Lopes, 2007), afetando dessa forma, a qualidade e segurança dos preparados fitoterápicos. Além disso, demonstram a necessidade de selecionar corretamente a parte a ser utilizada para determinada afecção e principalmente, seguir a posologia, a fim de evitar intoxicações ou reações adversas que podem aparecer devido ao emprego de doses inadequadas, modo de preparo incoerente e/ou períodos prolongados.

Em relação ao teste de micronúcleo, também se observou diferença de comportamento entre os extratos testados, quanto à incidência de micronúcleos, o que reforça a proposição de que os diferentes órgãos da planta ao apresentarem distintos componentes químicos possam apresentar diferentes ações, sejam elas tóxicas ou não (Gobbo-Neto \& Lopes, 2007). Os resultados demonstraram que 0 aumento da incidência de micronúcleos nos animais expostos ao tratamento com extrato hidroalcoólico das folhas de $E$. mulungu, ocorreu de forma dosedependente, quando comparado ao grupo controle. Além disso, os valores encontrados foram estatisticamente inferiores aos do controle positivo, demonstrando que, apesar do extrato ter capacidade de causar alterações no DNA, ele possui ação genotóxica inferior à ciclofosfamida (Figura 2). Essa diferença de comportamento entre o controle positivo e o extrato analisado, pode ser devido a um distinto mecanismo de ação entre os dois, ou a necessidade de uma concentração de extrato superior à analisada, para produzir efeito similar à ciclofosfamida.

Nos animais expostos ao tratamento com extrato hidroalcoólico das inflorescências de $E$. mulungu, observou-se que o aumento da incidência de micronúcleos se deu de forma independente entre as doses utilizadas, apresentando diferença estatística entre os tratamentos e o controle negativo. Os valores encontrados foram similares àqueles apresentados pelo grupo de animais expostos à ciclofosfamida (Figura 3).

Essa potencialidade genotóxica, encontrada nas folhas e inflorescências de E. mulungu, não foi encontrada por Matos \& Pantaleão (2008), ao analisarem o extrato alcoólico de E. velutina. Os resultados obtidos por esses autores indicaram que o extrato das folhas, nas concentrações de $25 \mathrm{mg}$ $\mathrm{kg}^{-1}, 50 \mathrm{mg} \mathrm{kg}^{-1}$ e $100 \mathrm{mg} \mathrm{kg}^{-1}$ não apresenta ação genotóxica, pois a incidência de micronúcleos não diferiu significativamente do grupo controle.

Provavelmente os metabólitos secundários envolvidos na genotoxicidade observada foram os flavonóides, que são encontrados em quantidades mais significativas tanto nas folhas quanto nas inflorescências e são considerados potencialmente mutagênicos, pois a ação terapêutica de alguns deles está associada a sua interação com o DNA (Henriques et al., 1991). Os taninos, que demonstraram atividade 


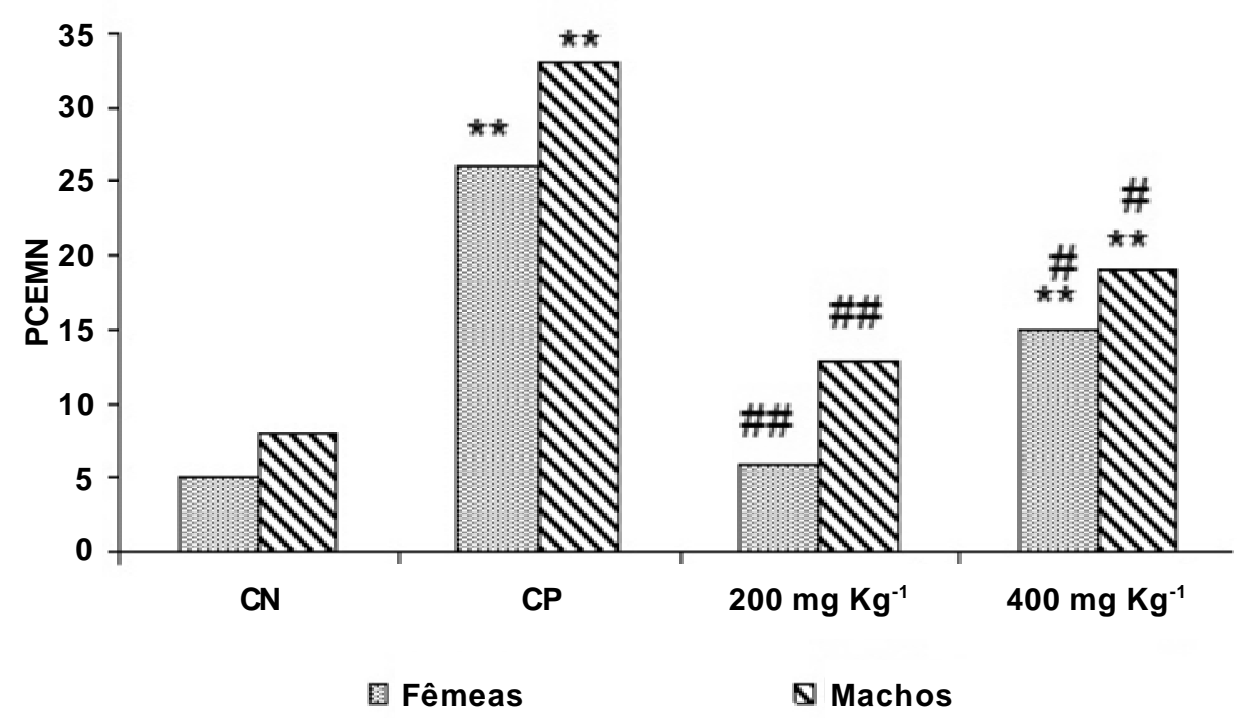

FIGURA 2. Frequência de eritrócitos policromáticos micronucleados (PCEMN) em medula óssea de camundongos machos e fêmeas, tratados com $200 \mathrm{mg} \mathrm{Kg}^{-1}$ e $400 \mathrm{mg} \mathrm{Kg}^{-1}$ de extrato hidroalcoólico das folhas de $E$. mulungu. Diferença significativa, pelo teste $\chi^{2}$, em relação ao controle negativo: ${ }^{* *} p<0,01$; Diferença significativa, pelo teste $\chi^{2}$, em relação ao controle positivo: $\# p<0,05 ; \# \# p<0,01$.

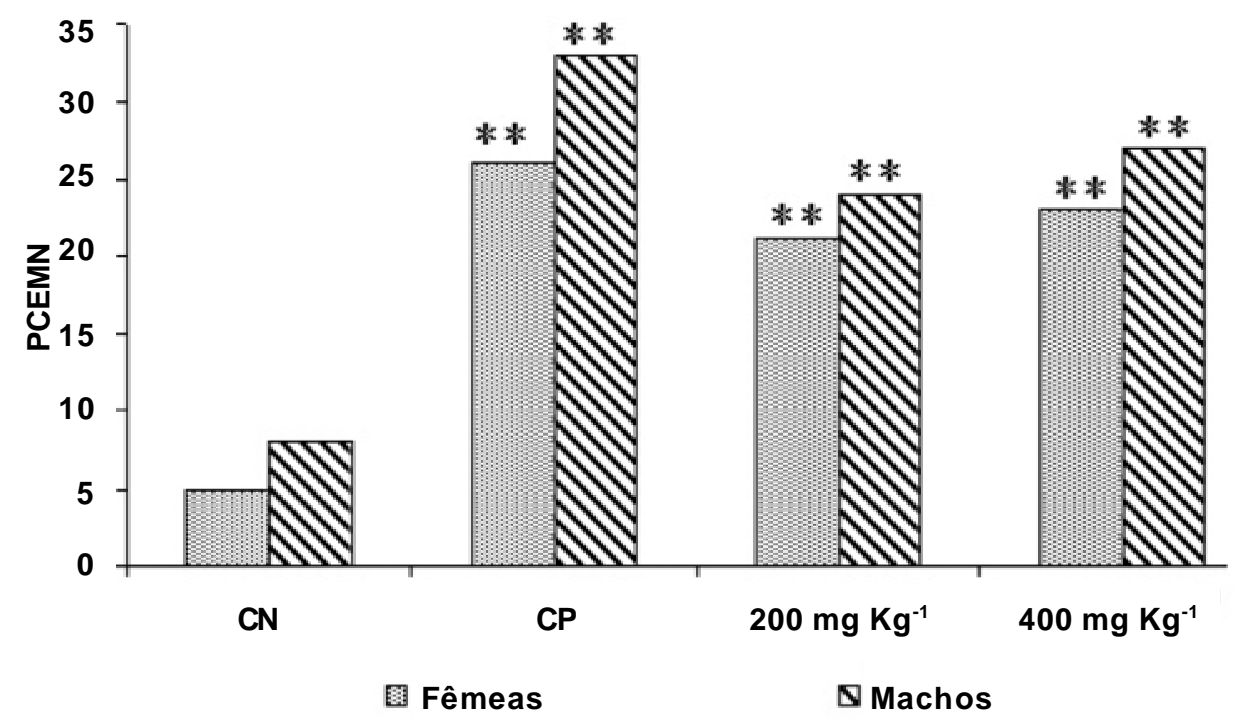

FIGURA 3. Frequência de eritrócitos policromáticos micronucleados (PCEMN) em medula óssea de camundongos machos e fêmeas, tratados com $200 \mathrm{mg} \mathrm{Kg}^{-1}$ e $400 \mathrm{mg} \mathrm{Kg}^{-1}$ de extrato hidroalcoólico das inflorescências de Erythrina mulungu Mart ex. Benth. Diferença significativa, pelo teste $\chi^{2}$, em relação ao controle negativo: ${ }^{* *} p<0,01$.

genotóxica causando quebras de fita simples (Labieniec \& Gabryelak, 2003), podem ter colaborado com essa mutagenicidade, agindo como mutagênicos ou potencializando os efeitos dos flavonóides.

Estes resultados reforçam que os efeitos dos produtos naturais resultam da interação entre os compostos químicos presentes no extrato e deles com o sistema biológico, onde os danos ocasionados por esses compostos estão relacionados com a estrutura química e os elementos presentes na molécula e às variações nas concentrações desses compostos. Esse fato reforça a proposta apresentada por Gobbo-Neto \& Lopes (2007) da necessidade de trabalhos que avaliem as diferenças de composição química entre órgãos de uma mesma planta, momentos distintos de coleta, ambientes diferentes de cultivo e até mesmo formas distintas de nutrição da planta utilizada.

Analisando a relação entre a porcentagem de eritrócitos policromáticos (EPC) e o total de eritrócitos (EPC+ENC), do extrato da folha (Figura 4) e da inflorescência (Figura 5) de E. mulungu, não se 


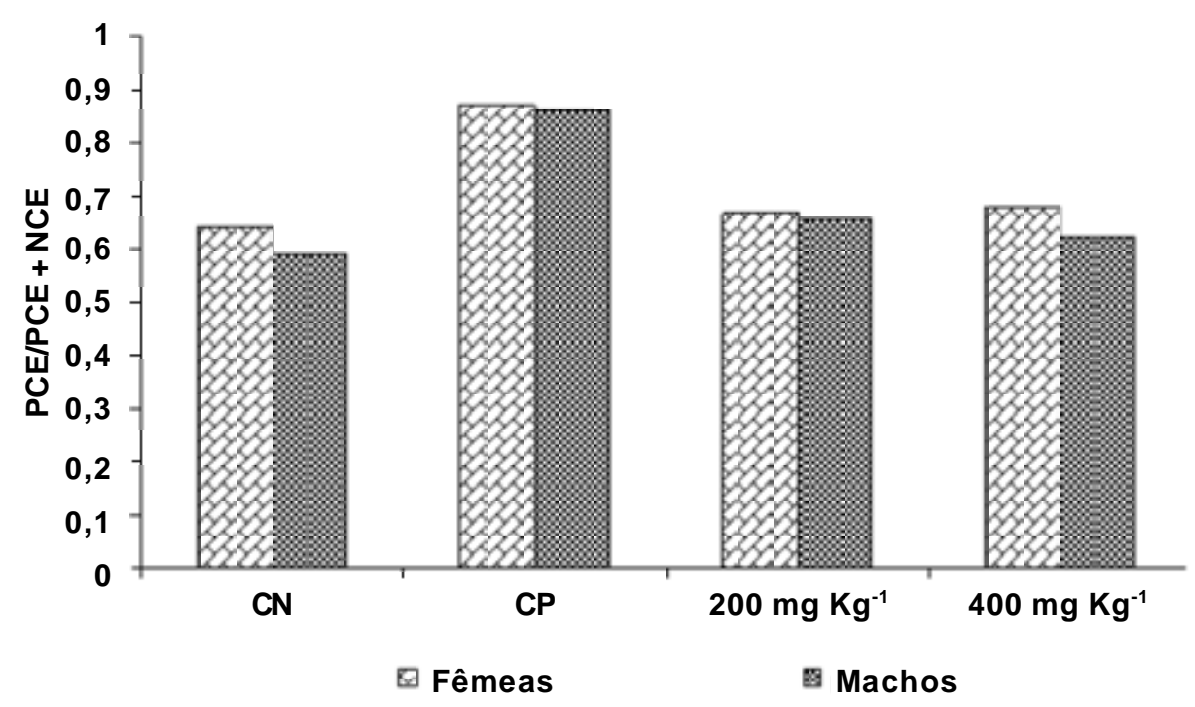

FIGURA 4. Relação entre eritrócitos policromáticos (PCE) e total de eritrócitos (PCE+NCE) em medula óssea de camundongos machos e fêmeas, tratados com $200 \mathrm{mg} \mathrm{Kg}^{-1}$ e $400 \mathrm{mg} \mathrm{Kg}^{-1}$ de extrato hidroalcoólico das folhas de Erythrina mulungu Mart ex. Benth.

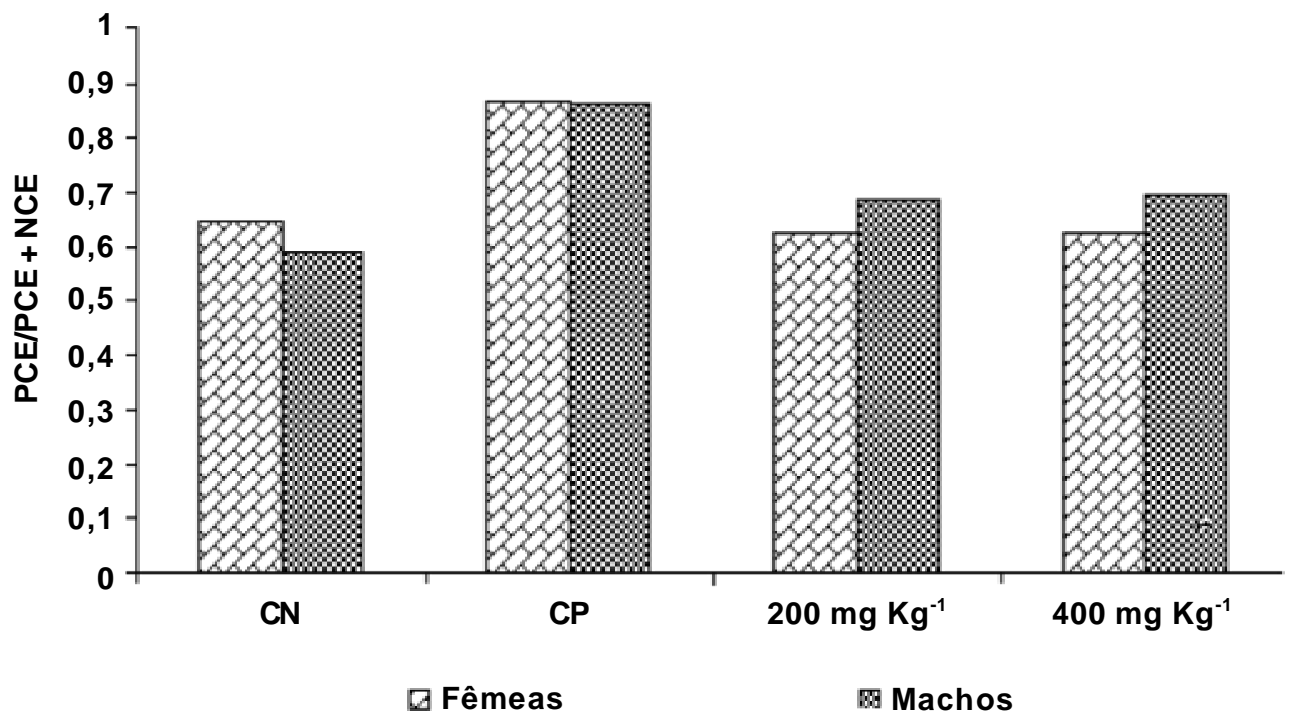

FIGURA 5. Relação entre eritrócitos policromáticos (PCE) e total de eritrócitos (PCE+NCE) em medula óssea de camundongos machos e fêmeas, tratados com $200 \mathrm{mg} \mathrm{Kg}^{-1}$ e $400 \mathrm{mg} \mathrm{Kg}^{-1}$ de extrato hidroalcoólico das inflorescências de Erythrina mulungu Mart ex. Benth.

constatou diferença significativa em relação ao controle negativo, em nenhum dos extratos.

A razão EPC/EPC+ENC pode indicar a citotoxicidade de uma substância, pois o decréscimo dessa relação indica que a substituição dos EPC, originados do eritoblasto, está deprimida. Dessa forma, esses resultados, que não demonstram redução na relação, indicam que os extratos analisados não estão afetando a maturação dos EPC, nem a formação no ciclo mitótico seguinte, não exibindo atividade citotóxica.

Assim, observa-se que apesar da folha e inflorescência apresentarem resposta diferenciada com relação à $\mathrm{DL}_{50}$, ambas apresentaram ausência de citotoxicidade em medula óssea de roedores. Contudo, folha e inflorescência demonstraram, nas concentrações utilizadas, capacidade de alteração no DNA, sendo essa característica dose-dependente e independente da dose, respectivamente, caracterizando-as como potencialmente genotóxicas. Portanto, pode-se concluir que o uso de preparações à base de $E$. mulungu devem ser feitas com cautela e observadas as doses utilizadas, pois mesmo não produzindo um efeito tóxico ou citotóxico agudo, o risco de mutagenicidade não deve ser descartado e tal situação poderá ser mais grave quando do uso crônico dessa planta. 


\section{AGRADECIMENTO}

Ao Fundo de Apoio à Ciência e Tecnologia do Município de Vitória - FACITEC, pelo apoio financeiro para a realização deste trabalho.

\section{REFERÊNCIA}

ALVES, N.D.C. Avaliação da adequação técnica das indústrias de medicamentos fitoterápicos e oficinais do estado do Rio de Janeiro a partir dos instrumentos regulamentatórios específicos. 2004. 83p. Dissertação (Programa de Pós Graduação em Vigilância Sanitária) Instituto Nacional de Controle de Qualidade em Saúde, Fundação Oswaldo Cruz, Rio de Janeiro.

ALMEIDA, E.E. Caracterização farmacognóstica da espécie Erythrina falcata Benth., Fabaceae. Revista Brasileira de Farmacognosia, v.20, n.1, p.100-5, 2010. ARAUJO NETO, V. et al. Prospecção fitoquímica e avaliação da atividade antioxidante do extrato das folhas de Erythrina velutina Willd. In: ENCONTRO DE INICIAÇÃO CIENTÍFICA, 18 E ENCONTRO DE PÓSGRADUAÇÃO, UNIVERSIDADE FEDERAL DE SERGIPE, 4., 2008, Sergipe. Resumo... Sergipe: Disponível em: <www.posgrap.ufs.br/down/Livro_Resumos_18EIC_ 4EPG.pdf>. Acesso em: 10 nov. 2008. p.598.

BARBOSA, W.L.R. Manual para análise fitoquímica e cromatográfica de extratos vegetais. Revista Científica da Universidade Federal do Pará, v.4, p.1-19, 2004.

BEIGUELMAN, B. Curso prático de bioestatística. 5.ed. Ribeirão Preto: FUNPEC, 2006. 274p.

BIESKI, I.G.C. Plantas medicinais e aromáticas no sistema único de saúde da região sul de Cuiabá- MT. 2005. 92p. Monografia (Pós-Graduação Lato Sensu em Plantas Medicinais: manejo, uso e manipulação) Departamento de Agricultura, Universidade Federal de Lavras, Lavras.

CAPASSO, R. et al. Phytotherapy and quality of herbal medicines. Fitoterapia, v.71, p.S58-S65, 2000.

CARVALHO, J.E. Toxicidade pré-clínica: fitoterápicos e alimentos com propriedades funcionais ou de saúde. 2004. Disponível em: <www.abma.com.br/2004/notes/ 205.pdf>. Acesso em: 7 mar. 2008.

CERUTTI, S.M. et al. Análise da toxicidade aguda do extrato hidroalcoólico bruto de Erythrina falcata em camundongos (Mus musculus). Revista de Farmácia e Biologia Lecta-USF, v.18, n.2, p.75-83, 2000.

FAGUNDES, F.A. et al. Annona coriacea induz efeito genotóxico em camundongos. Revista Eletrônica de Farmácia, v.2, n.1, p.24-9, 2005.

GARÍN-AGUILAR, M.E. et al. Effect of crude extracts of Erythrina americana Mill. on aggressive behavior in rats. Journal of Ethnopharmacology, v.69, p.189-94, 2000. GOBBO-NETO, L.; LOPES, N.P. Plantas medicinais: fatores de influência no conteúdo de metabólitos secundários. Química Nova, v.30, n.2, p.371-81, 2007. HENRIQUES, J.A.P. et al. Genotoxic effect of alkaloids. Memórias do Instituto Oswaldo Cruz, v. 86, p.71-4, 1991. LABIENIEC, M.; GABRYELAK, T. Effects of tannins on chinese hamster cell line B14. Mutation Research, v.539, n.1, p.127-35, 2003.

LEITE, E.M.A.; AMORIM, L.C.A. Noções básicas de toxicologia. Universidade Federal de Minas Gerais. 2006. Disponível em: <http://www.farmacia.ufmg.br/lato/ Apostila\%20Toxicologia\%20Geral\%20.doc>. Acesso em: 10 mar. 2008.

LEITE, K.R. et al. Avaliação da atividade mutagênica e genotóxica de Ginkgo biloba L. pelo teste do micronúcleo em camundongos. Revista de Biologia Neotropical, v.3, n.2, p.157-62, 2006.

LIMA, M.R.F. et al. Anti-bacterial activity of some Brazilian medicinal plants. Journal of Ethnopharmacology, v.105, p.137-47, 2006.

LORENZI, H.; MATOS, F.J.A. Plantas medicinais no Brasil: nativas e exóticas cultivadas. São Paulo: Instituto Plantarum, 2002. 544p.

MATOS, F.S.; PANTALEÃO, S.M. Avaliação do efeito genotóxico de Erythrina velutina pelo teste de micronúcleo in vivo. In: ENCONTRO DE INICIAÇÃO CIENTÍFICA 18 E ENCONTRO DE PÓS-GRADUAÇÃO, UNIVERSIDADE FEDERAL DE SERGIPE, 2008. Disponível em: <http:/www.posgrap.ufs.br/down/Livro_ Resumos_18EIC_4EPG.pdf>. Acesso em: 10 nov. 2008. PINO-RODRÍGUEZ, S. et al. Preliminary phytochemical screening and in vitro antitherpe activity of Erythrina fusca Lour. Acta Farmacéutica Bonaerense, v.23, n.2, p.4538, 2004.

RIBEIRO, L.R. Teste do micronúcleo em medula óssea de roedores in vivo. In: RIBEIRO, L.R.; SALVADORI, D.M.F.; MARQUES, E.K. Mutagênese Ambiental. Canoas: ULBRA, 2003. p.173-200.

SAIDU, K. et al. Antiplasmodial, analgesic, and antiinflammatory activities of the aqueous extract of the stem bark of Erythrina senegalensis. Journal of Ethnopharmacology, v.71, p.275-80, 2000.

SILVA, F.T. Avaliação clínica da potencial atividade ansiolítica do extrato seco de Erythrina velutina. 2008. 22p. Relatório Final (Projeto de Pesquisa) Laboratório de Fisiologia do Comportamento, Universidade Federal de Sergipe, São Cristóvão. Disponível em: <www.fapitec.se.gov.br/modules/ wfdownloads/visit.php?cid=11\&lid=234>. Acesso em: 10 nov. 2008.

SILVA, S.R. et al. Plantas medicinais do Brasil: aspectos gerais sobre legislação e comércio. Brasília: Ministério de Cooperação Econômica e Desenvolvimento da Alemanha e IBAMA, 2001. 44p.

TUROLLA, M.S.R.; NASCIMENTO, E.S. Informações toxicológicas de alguns fitoterápicos utilizados no Brasil. Revista Brasileira de Ciências Farmacêuticas, v.42, n.2, p.289-306, 2006. 